\title{
Initial characterization of Pf62, a novel protein of Plasmodium falciparum identified by immunoscreening
}

\author{
Eva M. Moyano • Luis Miguel González • \\ Estrella Montero • Laureano Cuevas • \\ Esperanza Perez-Pastrana • Ysmael Santa-Maria • \\ Agustín Benito
}

Received: 26 November 2008 / Accepted: 8 January 2009 /Published online: 27 January 2009

(C) The Author(s) 2009. This article is published with open access at Springerlink.com

\begin{abstract}
In order to find new antigens from Plasmodium falciparum, a complementary DNA (cDNA) library was constructed and screened. The study of expression library of $P$. falciparum was performed in an attempt to identify new antigens that could have potential relevance for the falciparum-malaria diagnosis and/or protection. Between the positive clones detected (ring erythrocyte surface antigen, merozoite erythrocyte surface antigen, RHOP H3, CSP, LSA), a new gene that correspond to a new protein (Pf62) was isolated and characterized. This antigen was useful for the diagnosis of malaria in enzyme-linked immunosorbent assay tests. The cDNA corresponding to this antigen and structure of the gene were characterized. Pf62 is a single copy gene that contains one exon. The Pf62 cDNA has an open reading frame of 1,599 nucleotides that code for a putative protein of 532 amino acids with a predicted molecular mass of $62 \mathrm{kDa}$. The polypeptide contains in the central section two regions of repeats of 21 and 19 amino
\end{abstract}

Nucleotide sequence data reported in this paper are available in the Genbank database under the accession number AJ 493426.

E. M. Moyano $\cdot$ A. Benito $(\bowtie)$

Centro Nacional de Medicina Tropical,

Instituto de Salud Carlos III,

Sinesio Delgado, 6; Pabellón 13,

28020 Madrid, Spain

e-mail: abenito@isciii.es

L. M. González · L. Cuevas · E. Perez-Pastrana • Y. Santa-Maria Centro Nacional de Microbiología,

Instituto de Salud Carlos III,

28220 Majadahonda,

Madrid, Spain

E. Montero

Department of Blood-Borne Parasites,

Lindsley Kimball Research Institute, New York Blood Center,

New York, NY 10021, USA acids, respectively. The localization of the Pf62 protein was performed by immunoblot, indirect immunofluorescence assay and immunoelectron microscopy. Pf62 is localized in the cytoplasm of the parasite and also on the surface of the infected erythrocyte. Serologic assays by using synthetic peptides designed from different antigenic regions of the Pf62 protein resulted in acceptable data of sensitivity and specificity in symptomatic malaria patients.

\section{Introduction}

Despite more than 100 years of research, malaria remains a leading cause of morbidity and mortality worldwide. Although the areas where transmission takes place have been reduced and confined to the tropical areas, the number of people at risk has grown to about 3 billion, and it is expected that this will continue to increase. Not only does malaria cause around 500 million cases every year and between 1 and 3 million deaths, it also carries a huge burden that impairs the economic and social development of large parts of the planet. The failed attempt to eradicate malaria gave way to the control policy that was followed by a huge resurgence of malaria during the late 1970s and 1980s. Together with the emergence and spread of resistance to chloroquine and the weak health infrastructure in many of the endemic countries, particularly in Africa, the malaria situation worsened worldwide (Guinovart et al. 2006).

Misdiagnosis of malaria results in significant morbidity and mortality. Rapid, accurate, and accessible detection of malaria parasites has an important role in addressing this and in promoting more rational use of increasingly costly drugs in many endemic areas. The conventional microscopic examination of thin and thick blood films demonstrates the presence of the parasite. This method is used to 
confirm the diagnosis of malaria, but it is a labor-intensive procedure and relies upon subjective interpretation. To overcome these limitations, fast and reliable methods for malaria diagnosis have recently been introduced (Bell et al. 2006). The search of new malaria antigens for rapid diagnostic technologies (RDTs) is necessary to increase the number and quality of the field malaria diagnostic tests. RDTs are mainly based on detect either histidine-rich protein 2 , the parasite-specific lactate deshidrogenase, or aldolase, which are produced in the erythrocytic cycle.

One of the strategies to search new antigens is the use immunoscreening of expression libraries to identify Plasmodium falciparum erythrocytic stage antigens. Several studies by using this technology have been reported (Kim et al. 2004; Lobo et al. 1994), and several antigens have been identify as ring erythrocyte surface antigen (RESA), $P$. falciparum asparagine-rich protein, merozoite erythrocyte surface antigen (MESA), heath shock protein 70 (HSP $70) \ldots$. On the other hand, identification of new antigens will permit to perform protection assays as vaccine candidates. Although all of the experimental vaccines that are currently under development are based on approximately 25 parasite antigens, it not clear whether they overlap with a subset or any of the antigens that induce the most protective naturally acquired immune responses. Whole genome sequencing has now provided the complete gene repertoire of $P$. falciparum and has opened the way to identify protective antigens among the approximately 6,000 parasite proteins.

In this study, we have carried out the identification and the initial characterization of a new protein of $P$. falciparum. Pf62 antigen was identified from a complementary DNA (cDNA) expression library of the erythrocytic stages of $P$. falciparum, with the aim to increase the arsenal of proteins that could be used in the development of both new malaria rapid diagnostic tests as useful tools to malaria diagnosis and possible vaccine candidates respectively. This manuscript describes the first approximation to characterization of Pf62, a novel gene encoding for a protein, which has the potential of being an efficient antigen for the diagnosis of malaria patients. Due to the difficulties found to clone and obtain the recombinant protein, we decide to change the strategy designing synthetic peptides according to antigenicity index and its posterior immunization of the rabbits to obtain immune sera. These sera were used for ultrastructural localization of the Pf62 native protein by immunoelectron microscopy.

\section{Materials and methods}

Parasites propagation

P. falciparum Dd2, a clone resistant to chloroquine, mefloquine, and pirymethamine coming from southeast
Asia and derived from the clone Indochina III/CDC (Guinet et al. 1996), was maintained in culture in human erythrocytes incubated at $37^{\circ} \mathrm{C}$ in RPMI 1640 medium supplemented with human serum and gas mixture $3 \%$ carbon dioxide, $1 \%$ oxygen, and $96 \%$ nitrogen). Fresh human erythrocytes were added at 3 or 4 days interval. The parasites continued to reproduce in their normal asexual cycle every $48 \mathrm{~h}$ approximately.

Enrichment of parasite-infected red blood cells by the magnetic method

One milliliter of the $10 \%$ suspension of erythrocytes was applied to a LD column assembled in a magnetic unit (Miltenyi Biotec) and washed with $20 \mathrm{ml}$ phosphate-buffered saline (PBS) to remove non-infected erythrocytes and white blood cells (WBCs). After the effluent from the column became almost colorless, the magnet was removed, and the cells retained in the column were eluted with $1 \mathrm{ml}$ PBS. Thus, the parasite-infected red blood cell (PRBC)-enriched fraction was obtained. The percentages of PRBCs to total red blood cells and the ratio of WBCs/PRBCs were determined on Giemsa-stained blood films (Trang et al. 2004).

\section{Human sera}

Sera were supplied by the Parasitology Department, Centro Nacional de Medicina Tropical, Instituto de Salud Carlos III, a Reference Laboratory which receives samples from malaria-suspected patients from different hospitals of Spain. Two class of sera were used in the study: (a) a mixture of ten sera from immunofluorescence assay (IFA)-positive patients (dilution titers $\geq 1 / 1,024$ ) was used for immunoscreening of the cDNA library and (b) 174 sera classified in the following: 110 sera of the whole were from individuals with IFA and PCR confirmed malaria, 30 sera from individuals with other parasitic diseases confirmed by serological methods (leishmaniasis $(n=10)$, Chagas disease $(n=10)$, toxoplasmosis $(n=10))$, and 34 negative control sera from Spanish healthy individuals without contact with endemic areas. Negative controls were used in order to establish suitable cut-off values for the serological assays. Study was approved by the Ethic Committee of the Instituto de Salud Carlos III.

\section{Extraction of genomic DNA}

P. falciparum genomic DNA (gDNA) was isolated from blood-stage parasites (strain Dd2) cultured in vitro. The parasites were resuspended with $400 \mu \mathrm{l}$ of extraction buffer (100 mM Tris-HCl, pH 7.4, 100 mM NaCl, 10 mM EDTA, $\mathrm{pH}$ 8.0). Then, $1 \%$ SDS, K-Proteinase was added and incubated for $2 \mathrm{~h}$ at $55^{\circ} \mathrm{C}$. After incubation, RNAse 
$(100 \mu \mathrm{g} / \mathrm{ml})$ was added and left to react for $1 \mathrm{~h}$ at $55^{\circ} \mathrm{C} ; 0.1$ volume of potassium acetate was added and incubated in ice for $55 \mathrm{~min}$. The DNA was extracted and precipitated with phenol/chloroform and ethanol, respectively. The pellet was resuspended in Milli-Q sterile water (Millipore), the DNA concentration was determined by a spectrophotometer, and the samples were stored at $-20^{\circ} \mathrm{C}$.

\section{cDNA expression library}

Total RNA was prepared as previously described (RangelAldao et al. 1987) from P. falciparum erythrocytic stages. Messenger RNA (mRNA) was extracted as described by Avid and Leder (1972). A sample containing $2.2 \mu \mathrm{g}$ of mRNA was converted into double-stranded cDNA with the ZAP Express cDNA synthesis kit (Stratagene, CA, USA) according to the manufacturer's instructions and then ligated to the ZAP expression vector employing $\lambda$-ZAP Express library kit (Stratagene). The original library was amplified containing $4.2 \times 10^{8} \mathrm{pfu} / \mathrm{ml}$ and $31 \%$ of nonrecombinant phage.

Isolation and sequence analysis of $P$. falciparum Pf62 cDNA

cDNA library was screened using equal volumes of a pool of malaria positive sera. Clones of RESA, RHOP H3, HSP 70, MESA, LSA, and CSP recombinant antigens were detected. One positive clone (Pf62) was purified by repeated cycles of immunoscreening. Recombinant pBKCMV plasmids were excised from positive phages. The size of the Pf62 positive clone was determined by PCR using T3 and T7 universal primers and EcoRI/XhoI double digestion. The nucleotide sequence was determined by the dideoxy method (Sanger et al. 1977) using the Big-Dye Terminator Cycle Sequencing Ready Reaction Kit (PerkinElmer, Langen, Germany) and an Applied Biosystems 377 DNA sequencer (Perkin Elmer); however, the clone lacked 5' and $3^{\prime}$ ends. Thus, in order to obtain a complete cDNA sequence, the $5^{\prime}$ and $3^{\prime}$ ends were amplified by PCR using specific primers based on the genomic DNA sequence of the clone 3D7 P. falciparum provided by the PlasmoDB database. We used the following primers: the forward primer Pf62 FULL START (5'GAGAGAGACCCGGGAT GATGGAAGG $3^{\prime}$ ) and reverse primer Pf62 FULL STOP (5' GAGAGAGACTCGAGTTAATTAAATACAG 3'). To amplify the complete sequence of $P$. falciparum Pf62, genomic DNA extraction was carried out based on the method described above from cultures of $\operatorname{Dd} 2$ clone. The amplified product of 1,599 bp (Genbank accession no. AJ 493426) and the predicted amino acid sequence comparisons were carried out with the EMBL and SWISS-PROT databanks using software packages from Genetic Computer
Group (Devereux et al. 1984). The bioinformatic program Genscan of the Genemachine server (Makalowska et al. 2001) was used to predict a possible open reading frame (ORF) and the organization of the Pf62 gene. Prosite (Bucher and Bairoch 1994) and Psipred (Jones 1999) bioinformatic programs were used to study functional motifs and to predict the secondary structure of Pf62 protein. The primers were synthesized by Roche Molecular Biochemicals, Barcelona, Spain. The PCR experiments were performed on a GeneAmp PCR System 2400 (Perkin Elmer, NJ, USA).

Southern blotting, labeling, and hybridization procedures

Aliquots of $P$. falciparum gDNA $(0.5 \mu \mathrm{g} /$ digestion $)$ prepared as described previously (Sambrook et al. 1989) were digested completely with various restriction endonucleases, AluI, ApoI, EcoRI, HindIII, HinfI, and Ssp I (Roche Diagnostics), according to the manufacturer's instructions. The digested DNA samples were visualized by electrophoresis in $0.8 \%$ agarose gels and transferred to positively charged nylon membranes (Hybond nylon ${ }^{+}$, Amersham) as described (Maniatis et al. 1982). The Pf62 incomplete cDNA probe was labeled with digoxigenin-11-d UTP (Roche Diagnostics) by random primer method, according to the manufacturer's instructions. The labeled probe was incubated under high-stringency conditions at $65^{\circ} \mathrm{C}$. After hybridization, the filter was washed in $5 \times$ SSC, $0.1 \% N$-lauryl sarcosine, $0.02 \%$ SDS, and $1 \times$ blocking reagent (Roche Diagnostics) at $65^{\circ} \mathrm{C}$ for 10 min. A second wash was done in $0.2 \times \mathrm{SSC}$ and $0.1 \%$ SDS at $65^{\circ} \mathrm{C}$ for $40 \mathrm{~min}$. The immunodetection was carried out with antidigoxigenin conjugated with alkaline phosphatase, and the immune complexes were visualized using the chemiluminescence substrate CSPD (Roche Diagnostics) on X-ray film (Amersham), with an intensifying screen at room temperature for $15 \mathrm{~min}$, as described by the manufacturer's instructions.

Synthesis of peptides derived from Pf62 deduced amino acid sequence

The difficulties found to express the whole protein made us use the strategy of synthesizing synthetic peptides to serological studies. Taking into account the full length of the Pf62 deduced amino acid sequence; three peptides were designed according to the Jameson-Wolf antigenicity index (Jameson and Wolf 1988). The peptides were synthesized by the Institute of Health Carlos III, and their sequences were as follows: Pf62 ZR ${ }_{273}$ PQAEKDASKLTTTYDQTKEVK 292 , repeated three times in the sequence, Pf62 ZR1 ${ }_{315}$ PQAEK DALAKTENQNGELL ${ }_{333}$, repeated two times in the sequence and Pf62 ZR2 ${ }_{374}$ PQAEKDALAKTENQSGELL ${ }_{392}$. 
ELISA with peptides Pf62 ZR, Pf62 ZR1, and Pf62 ZR2

Peptides Pf62 ZR, Pf62 ZR1, and Pf62 ZR $(0.2 \mu \mathrm{g} / \mathrm{ml}$, $100 \mu \mathrm{l} /$ well $)$ were diluted in coating buffer $(0.1 \mathrm{M}$ carbonate/bicarbonate $\mathrm{pH}$ 9.6) and then used to coat 96 well plates (Maxisorp ${ }^{\circledR} 2$, flat bottom, Nunc) overnight at $4^{\circ} \mathrm{C}$. Unbound antigen was removed by washing the wells with PBS, pH 7.3 containing $0.05 \%(w / v)$ Tween ${ }^{\circledR} 20$. After washing, $100 \mu \mathrm{l}$ of experimental serum samples (diluted 1/100) per well was added an incubated for $1 \mathrm{~h}$ at $37^{\circ} \mathrm{C}$. Each sample was run in duplicate. After washing, $100 \mu \mathrm{l}$ per well of goat antihuman IgG conjugated with peroxidase $\left(\mathrm{H}\right.$ and $\mathrm{L}$ chains Pierce $\left.^{\circledR}\right)$ diluted $1 / 5,000$ were added and incubated for $1 \mathrm{~h}$ at $37^{\circ} \mathrm{C}$. The plates were washed, and $100 \mu \mathrm{l} /$ well of substrate (ABTS in $10 \mathrm{ml}$ citrate-phosphate-perborate buffer) was added, and the plates were incubated for $15 \mathrm{~min}$ at room temperature. The optical density was read at $405 \mathrm{~nm}$ on a microplate reader (Mios, Merk ${ }^{\circledR}$ ). A sample was considered positive if the specific absorbance was greater than the cut-off values. The cut-off value was obtained with the mean value of 34 negative serum samples plus three standard deviations (SD). Cut-off values: Pf62 ZR=0.195.

\section{Preparation of rabbit Pf62-specific antiserum}

Two 3-month-old female New Zealand White rabbits were immunized by subcutaneous injection of $120 \mu \mathrm{g}$ of Pf62 ZR peptide conjugated to ovalbumin and to KLH (Keyhole limpet hemocyanin; Pierce ${ }^{\circledR}$ ) carriers in Freund's complete adjuvant $\left(\right.$ Difco $\left.^{\circledR}\right)$. Before the first immunization, $10 \mathrm{ml}$ was obtained from each rabbit as negative control. Animals were boosted two times with $120 \mu \mathrm{g}$ of Pf62 ZR peptide conjugated to the carriers in Freund's incomplete adjuvant (Difco $\left.{ }^{\circledR}\right) 6$ weeks postinjection by intramuscular injections. Fifteen days after the third immunization, the animals were bled. The serum obtained is referred to as anti-Pf62. The serum titer was determined by enzyme-linked immunosorbent assay (ELISA).

\section{SDS-PAGE and western blot analysis}

One-dimensional sodium dodecyl sulfate- $10 \%$ polyacrylamide gel electrophoresis (SDS-10\% PAGE) and western blotting of P. falciparum Dd2 clone protein extract $(20 \mu \mathrm{g})$ were carried out. The separated proteins were transferred to nitrocellulose membranes (Schleicher \& Schuell, Protran ${ }^{\circledR}$ ) with a semidry blotting apparatus (Trans-blot ${ }^{\circledR}$ SD Semidry, Bio-Rad ${ }^{\circledR}$ ) during $30 \mathrm{~min}$ at $10 \mathrm{~V}$. The filters were blocked with PBS containing $3 \%$ BSA at $4{ }^{\circ} \mathrm{C}$, overnight. During the next day, they were rinsed in PBS containing $0.05 \%(w / v)$ Tween ${ }^{\circledR} 20$ and incubated with anti-Pf62 polyclonal rabbit antiserum diluted 1/50 in the blocking solution for $1 \mathrm{~h}$ at room temperature. After washing, goat antirabbit $\mathrm{IgG}$ conjugated to peroxidase ( $\mathrm{H}$ and $\mathrm{L}$ chains; Pierce) diluted 1/5,000 was added and incubated for $1 \mathrm{~h}$ at room temperature. The nitrocellulose membrane was washed, and the reaction was developed with $\mathrm{DAB}$ substrate diluted in peroxide buffer (Pierce ${ }^{\circledR}$ ) as described by the manufacturer's instructions.

\section{Indirect immunofluorescence assay}

Smears of RBC infected with P. falciparum clone Dd2 were fixed with ice-cold $100 \%$ acetone for $5 \mathrm{~min}$ and incubated with rabbit anti-Pf62 polyclonal antiserum (diluted 1/50 in PBS-BSA), $1 \mathrm{~h}$ at $37^{\circ} \mathrm{C}$. After, this smears were washed with 3\% $(w / v)$ BSA (Sigma) diluted in PBS. As secondary antibody, we used goat antirabbit IgG labeled with fluorescein (Pierce) diluted $1 / 500$ and incubated for $50 \mathrm{~min}$ at $37^{\circ} \mathrm{C}$ in blocking solution with Evans Blue $0.05 \%$. After washing, $10 \mu \mathrm{g} / \mathrm{ml}$ propidium iodide diluted in mounting solution (glycerol/PBS pH 9.2) was added in order to label the DNA. Dual color fluorescence images were captured using a Zeiss Axioskop (Zeiss ${ }^{\circledR}$ ) fluorescence microscope.

\section{Immunoscanning electron microscopy}

The immunolocalization SEM procedures were performed as described elsewhere (Herrera et al. 1998) Briefly, red blood cells uninfected or infected with P. falciparum were subjected to a series of washings (PBS $+0.13 \% \mathrm{NaN}_{3}+1 \%$ $\mathrm{BSA}+1 \% \mathrm{AB}$ human serum as washing buffer) and incubations with antibodies (PBS $+0.13 \% \mathrm{NaN}_{3}+5 \%$ $\mathrm{BSA}+4 \% \mathrm{AB}$ human serum as incubation buffer), collecting the samples in between by centrifugation $\left(230 \times g, 10 \mathrm{~min}, 21^{\circ} \mathrm{C}\right)$. Rinsed samples were incubated with $100 \mu \mathrm{l}$ of the primary antibody (anti-Pf62 rabbit specific antiserum diluted $1 / 10$ in incubation buffer) for $30 \mathrm{~min}$ at room temperature. After rinsing (three times) in washing buffer, the samples were incubated with $100 \mu$ of a secondary antibody for gold labeling (goat antirabbit IgG coupled to 30-nm-diameter colloidal gold particlesAmersham Pharmacia-Biotech - diluted 1/10 in incubation buffer) at room temperature for $60 \mathrm{~min}$. After two washings, the samples were fixed with $2 \%$ glutaraldehyde- $0.1 \mathrm{M}$ sodium cacodylate buffer-pH 7.4 for $1 \mathrm{~h}$ at $4^{\circ} \mathrm{C}$ and rinsed with chilled $0.1 \mathrm{M}$ sodium cacodylate buffer-pH 7.4 supplemented with $4.5 \%$ saccharose. The cells were then dehydrated in a graded ethanol series, mounted onto formvar-carbon-coated 400-mesh electron microscopy nickel grids using poly-L-lysine, dried in a critical point dryer (Balzer $030 \mathrm{CPD}$ ), and coated with a 15-nm carbon layer in a high vacuum coating unit (Balzers 080). The samples were analyzed in SEM mode under a CM-12 TEM/STEM 
Philips Electron Microscope attached with secondary electron (SE) and backscattered electron (BSE) detectors.

Immunotransmission electron microscopy

For the immunogold detection of the Pf62 proteins on ultrathin sections, the cells were fixed in $2 \%$ paraformaldehyde, $0.2 \%$ glutaraldehyde in $0.1 \mathrm{M}$ sodium cacodylate buffer, $60 \mathrm{~min}$ at $4^{\circ} \mathrm{C}$, rinsed $(2 \times 30 \mathrm{~min})$ in chilled $0.1 \mathrm{M}$ sodium cacodylate buffer supplemented with $4.5 \%$ saccharose, and treated for low temperature embedding in hydrophilic acrylic resin (Lowicryl K4 M-Polyscience, Warrington, PA, USA) in order to preserve the antigen properties. Briefly, the samples were dehydrated starting with $50 \%$ ethylene glycol at $0^{\circ} \mathrm{C}$ and following by a graded ethanol $(50 \%-90 \%)$ series at $-35^{\circ} \mathrm{C}$, embedded in graded ethanol 90\%/Lowicryl series until pure Lowicryl resin and polymerized with a UV light at $-35^{\circ} \mathrm{C}$ and at room temperature. Ultrathin sections, obtained with a ultramicrotome (Ultratome, LKB), were mounted on 400 mesh nickel grids and processed for immunogold-labeling at room temperature, blocked (three times) in $100 \mu \mathrm{l}$ drops of blocking buffer (TBS (10 mM Tris- $\mathrm{HCl}, 9 \mathrm{mg} / \mathrm{ml} \mathrm{NaCl}$; $\mathrm{pH}$ 7.4), $0.2 \mathrm{mg} / \mathrm{ml} \mathrm{NaN}_{3}, 0.1 \%$ Tween $20 ; 20 \mathrm{mg} / \mathrm{ml}$ BSA), incubated $60 \mathrm{~min}$ on a $10 \mu \mathrm{l}$ drop of primary antibodies (anti-Pf62 rabbit specific antiserum, 1/5,000 in blocking buffer), washed (three times) in $100 \mu$ drops of washing buffer (TBS-NaN 3 -Tween; $2 \mathrm{mg} / \mathrm{ml} \mathrm{BSA}$ ), incubated $60 \mathrm{~min}$ on $10 \mu \mathrm{l}$ drops of secondary antibodies (goat antirabbit IgG coupled to 10-nm-diameter colloidal gold particles-Biocell Amersham Pharmacia-Biotech-diluted $1 / 10$ in washing buffer) and three times washing (washing buffer $+0.1 \%$ Triton $\mathrm{X}-100$ ) plus three times washing in double-distilled water. To contrast the sections, uranyl acetate $(1 \%$ in dd water) was used. The samples were analyzed in TEM mode under a CM-12 TEM/STEM Philips electron microscope.

\section{Results}

Identification and analysis of $P$. falciparum Pf62 cDNA

To identify novel antigen genes, a screening of $5 \times$ $10^{4}$ clones from the $P$. falciparum cDNA library with a pool of malaria patients sera yielded 35 promising signals. Of these, one molecule of $1.12 \mathrm{~kb}$ (Pf62) was sequenced and further characterized. This cDNA sequence had an incomplete open reading frame. In order to obtain the complete Pf62 sequence, a PCR was designed using standard PCR protocols, parasite gDNA, and primers were derived from both the $5^{\prime}$ and $3^{\prime}$ ends of the DNA sequence provided by Genbank database (Pf62 FULL STAR and Pf62 FULL STOP, Fig. 1). A variety of PCRs were carried out, and in all them, a band of $1.59 \mathrm{~kb}$ was obtained (Fig. 1). The sequencing of the fragment revealed the full Pf62 open reading frame sequence of 1,599 bp (Fig. 1). The ORF was coded for a putative protein of 532 amino acid residues with $62 \mathrm{kDa}$ theorical molecular mass and an isoelectric point of 5.53 (Genbank accession no. AJ 493426). The Pf62 primary structure amino acid sequence can be separated into three different linear domains: (1) amino-terminal domain, (2) central domain, and (3) carboxy-terminal domain. The central domain contains two regions of repeats of 21 and 19 amino acids, respectively. The first region contains three repeats with a consensus sequence: PQAEKDASKLTTTYDQTKEVK (positions 273-314 and 334-354). The second region contains three imperfect repeats with a consensus sequence: PQAEKDALAKTENQN/SGELL (positions 315-333 and 355-392). Using the bioinformatic program Prosite, various putative $N$-glycosylation sites of the Pf62 protein were identified in the residues $5,368,417,444$, and 451 . The study of the predicted secondary structure using the Psipred program revealed that Pf62 was a hydrophilic protein rich $\alpha$-helices and without $\beta$-sheets.

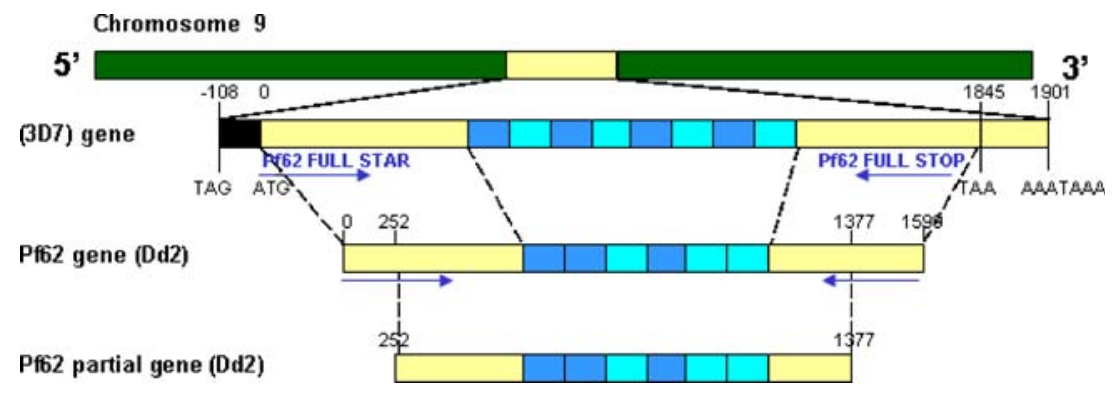

Fig. 1 Representation of genomic organization of the Pf62 gene. The gene for Pf62 is located on chromosome 9 of strain 3D7 P. falciparum. The Pf62 gene sequence consists of one exon in the 3D7 and Dd2 strains. The partial sequence of the clone obtained in the immunoscreening corresponds to $252-1,377 \mathrm{bp}$ or Pf62 gene. The primers used for genomic PCR (Pf62 FULL STAR and Pf62 FULL STOP) are designed on the sequence at the beginning and the end of the Pf62 gene. The size of fragments (base pair) is indicated. iMet-ATG, termination codon-TAA, and polyadenylation signal-AAATAAA positions are marked. The boxes in different colors correspond to the repeats regions 
Alignments of the $P$. falciparum DNA sequence and predicted amino acid sequence with the Genbank/EMBL and SWISS-PROT databanks did not show any similarity with sequences described in the databases.

Organization of the Pf62 gene

Pf62 gene was located in the chromosome 9 of $P$. falciparum genome. The comparison of the Pf62 cDNA with the homologous DNA sequence provided by the PlasmoDB database revealed that the full $P$. falciparum Pf62 genomic sequence spans approximately $2 \mathrm{~kb}$, with single exon and without introns. The locations of translation star codon (iMet), poly (a)-tail signals and stop codon are shown in the Fig. 1. These results were confirmed by the bioinformatic program Genscan. When Southern analysis was carried out with P. falciparum gDNA digested by AluI, ApoI, EcoRI, HindIII, HinfI, and SspI, using the Pf62 cDNA as a probe, the hybridization patterns obtained suggested that the Pf62 gene is a single copy gene (Fig. 2a). This result is consistent with the only presence of a homologous DNA sequence in the chromosome 9 from clone 3D7 $P$. falciparum (PlasmoDB database). Further more, nucleotide polymorphisms were observed among both sequences.

Localization of Pf62 native protein in extract cultures from $P$. falciparum

The rabbit anti-Pf62 antiserum identified a $62 \mathrm{kDa}$ protein on Western/blot analysis using extracts cultures from clon Dd2 P. falciparum (Fig. 2b). This antiserum was then used to localize the Pf62 native protein in cellular and subcellular studies.

\section{Cellular localization of Pf62 native protein}

The cellular localization of Pf62 was examined by indirect IFA. To determine the cellular localization of Pf62, IFA was performed on cultures containing rings, trophozoites and schizonts stages parasites ( $\mathrm{Dd} 2$ clone). The rabbit antiserum against Pf62 localized the native protein in all the stages. The fluorescence was clearly and preferentially localized on the surface as well as in the cytoplasm of infected erythrocytes (Fig. 3). The IFA was repeated using rabbit anti-Pf62 serum at multiple dilutions $(1: 10-1: 1,000)$ with identical results. The preimmune serum, used as a control, was negative in IFA.

Ultrastructural localization of the Pf62 native protein by immunoelectron microscopy

Immunotransmission electron microscopy (immuno-TEM) was used to analyze the ultrastructural localization of the Pf62 antigen. All the rabbit antisera prepared against

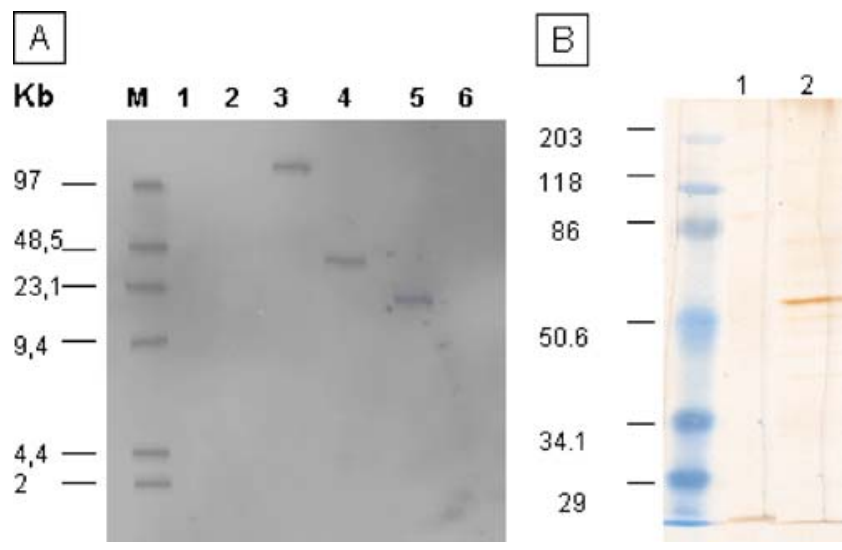

Fig. 2 Restriction, hybridization analyses, and expression of Pf62 in Dd2 strain $P$. falciparum from total DNA and extracts cultures respectively. a The $P$. falciparum gDNA $(0.5 \mu \mathrm{g} / \mathrm{lane})$ digested with AluI (lane1), ApoI (lane 2), EcoRI (lane 3), HindIII (lane 4), and HinfI (lane 5) were electrophoresed on $0.8 \%(w / v)$ agarose gel, blotted, and hybridized to the digoxigenin-11-dUTP-labeled incomplete Pf62 cDNA insert. b Protein samples $(20 \mu \mathrm{g})$ were charged in each lane, fractionated in $10 \%$ polyacrylamide gel, transferred to nitrocellulose membrane, and probed with specific antisera against the Pf62 protein (lane 2) and preimmune sera (lane1). The molecular markers positions are indicated on the left kilodaltons (prestained SDS-PAGE standards, broad range; Biorad $^{\mathbb{R}}$ )

recombinant peptide derived of the Pf62 protein repetitive domain reacted with ultrathin sectional material (the PRBCenriched fraction) containing asexual stages of the $\mathrm{Dd} 2$ clone, while the preimmune serum, used as control, gave a negative result. The gold particles were distributed by the parasite's cytoplasm and by the infected erythrocyte (Fig. 4), indicating the presence of the Pf62 protein of $P$. falciparum and confirming the IFA results but providing a more detailed analysis and an ultrastructural localization due to the higher resolution of the EM. This also suggests that these antibodies have the potential to recognize the Pf62 protein in its natural form and that they could be used in capture assays for the diagnosis of malaria.

In the present work, the immunoscanning electron microscopy (immuno-SEM) was carried out using the PRBC-enriched fraction and reveals the localization of the Pf62 protein on the outer surface membrane of the infected erythrocyte. The design of the used electron microscope permits to obtain at the same time the SE image of the cells showing their ultrastructure and the BSE-image that illustrates the distribution of the gold particles and therefore the localization of the Pf62 antigen against in which the primary antibodies were specifically raised (Fig. 5).

Immunogenicity of synthetic peptide constructs evaluated by ELISA

The difficulties found in the expression of the Pf62 protein made us change strategy and develop synthetic peptides. To 

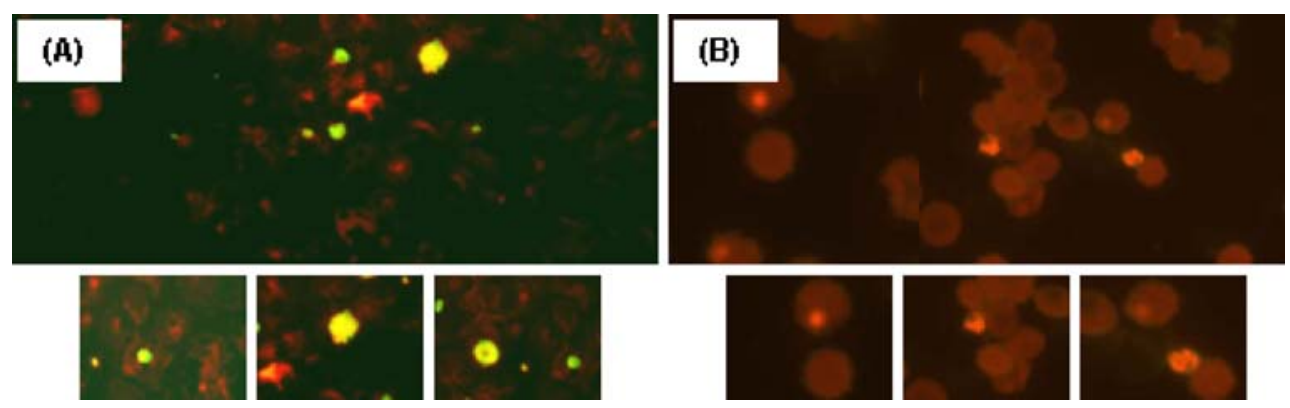

Fig. 3 Localization of the anti-Pf62 reactivity on asexual parasite stages by indirect immunofluorescence. Smears of parasite-infected red blood cells, strain Dd2, were reacted with rabbit anti-Pf62 polyclonal antisera. a Incubation with 1:50 dilution of antisera raised

against the Pf62 protein. b Incubation with preimmune rabbit serum at the same dilution, derived from the same rabbit used to derive Pf62 antibodies prior to the first immunization

study the immunogenicity of peptides derived from Pf62 protein of $P$. falciparum, the polyclonal antibodies obtained from rabbits immunized with different peptides corresponding to repeat sequences of Pf62 were tested by ELISA.

The experimental animals, immunized rabbits, produced specific antibodies against one of the Pf62 peptide constructs (Pf62 ZR). The results with the other peptides (Pf62 ZR1 and Pf62 ZR2) were negatives. In the present study, we explored the potential of synthetic peptide (Pf62 ZR) for usage in the diagnosis of malaria. When sera from malaria seropositive individuals to malaria were examined by ELISA for antibodies using Pf62 ZR peptide as antigen, the assay sensitivity was $59 \%$; however, using sera from symptomatic malaria patients, the sensitivity reached $70 \%$. When the Pf62 peptide was tested with sera from patients with other parasitic diseases as leishmaniasis, Chagas disease, and toxoplasmosis, specificities of $100 \%$ were obtained.

\section{Discussion}

In this work, an expression library of $P$. falciparum erythrocytic stages was performed in an attempt to identify

new antigens that could have potential relevance in immunodiagnosis and immunoprophylaxis of malaria. In effect, various examples have been reported in the literature about the immunoscreening of a $P$. falciparum spp. Expression libraries have been a tool used by others authors in order to identify useful antigens for the diagnosis of malaria patients as well as to see the usefulness in protection (Kim et al. 2004; Zhang et al. 1999; Lobo et al. 1994). We report the identification and characterization of the Pf62 gene that encoded a putative protein of 532 amino acids with two regions of repeats of 21 and 19 amino acids in the central region of the molecule. In fact, $P$. falciparum contains polypeptides with extensive sequence repeats and is sometimes extraordinary Kemp et al. (1990). These repeats are immunodominant in the sense that much of the human antibody response is directed against them. It has been observed that not many immune individuals have got very high levels of antibodies against many repetitive antigens. In addition, to the repetitive epitopes, P. falciparum encodes an enormous number of cross-reactive epitopes, which are also postulated to be responsible for the immune evasion (Anders 1986). The remarkable level of antigenic diversity among different strains of $P$.

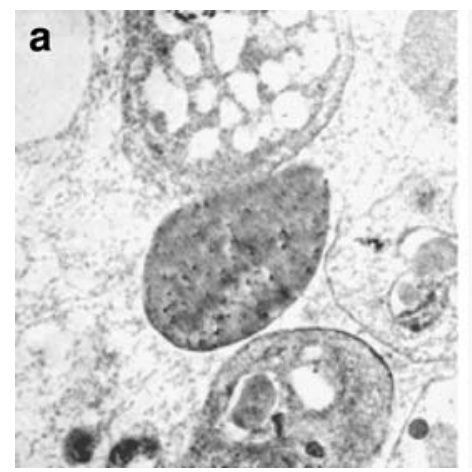

Fig. 4 Ultrastructural localization of Pf62 protein in different stages of $P$. falciparum. Transmission electron microscopy immunogoldlabeling (10 nm gold particles, arrows) in ultrathin sections. a General overview of parasite-infected RBCs $(\times 6,300$, original magnification).
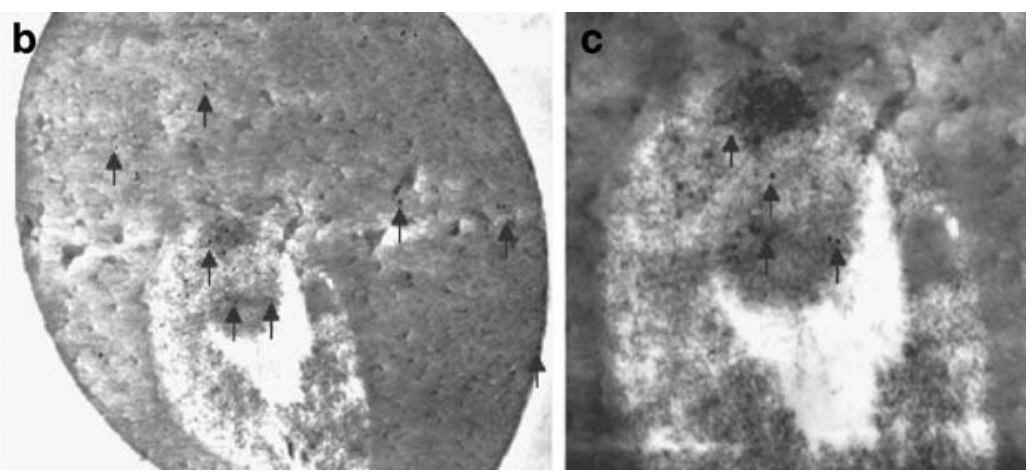

b The Pf62 protein is localized in the trophozoite and in the erythrocyte, both in the cell interior and surface. c The same trophozoite at higher magnification 
Fig. 5 Immunoscanning electron micrograph. Erythrocytes parasite-infected by $P$. falciparum. Left The backscattered electron detector identifies the bright signals from the gold particles that localize the Pf62 protein. Right The same field using the secondary electron detector that shows the ultrastructure of the erythrocytes

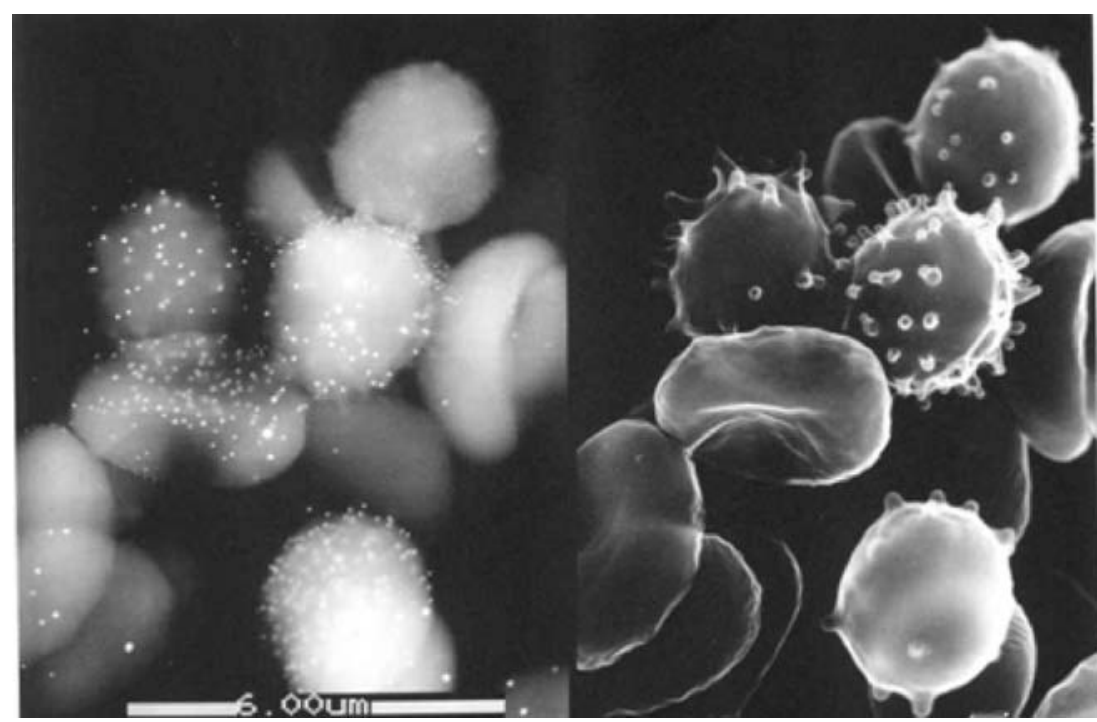

falciparum (Fenton et al. 1985; Tait 1981) reflects, at least in part, the repeat structure of these antigens.

Western-blot analysis using anti-Pf62 antiserum localized the native antigenic protein of $62 \mathrm{kDa}$ in extract cultures from $P$. falciparum. This antiserum was then used to localize the Pf62 native protein in cellular and subcellular studies by IFA, immuno-SEM, and immuno-TEM. All three methods showed the same tendency: Pf62 native protein was distributed by the parasite's cytoplasm and also on the surface membrane of the infected erythrocyte. There is considerable information available in literature concerning the disposition of parasite proteins in host cell plasma membranes. However, this information is confusing and conflicting (Wunderlich et al. 1988a, b). In truth, we do not know if the Pf62 protein is accessible from the outside in intact $P$. falciparum-infected erythrocytes because the host cell plasma membranes are artificially changed. This indicate that drying and fixing with acetone and/or ethanol induce changes in membrane organization, which make accessible parasite proteins normally buried in host cell plasma membranes (Wunderlich et al. 1988a). Therefore, the Pf62 protein could have cryptic disposition in intact host cell plasma membranes of $P$. falciparum-infected erythrocytes.

Finally, in the present study, we explored the potential of three peptides derived from the Pf62-deduced amino acid sequence for usage in the diagnosis of malaria. The peptides were designed in highly antigenic and repeated regions of Pf62. The peptide Pf62 ZR showed the best results when it was used in ELISA assays with a sensibility of $70 \%$ in symptomatic malaria patients and a specificity of $100 \%$. Also, the experimental animals, immunized rabbits, produced specific antibodies against one of the Pf62 peptide constructs (Pf62 ZR). The results with the other peptides (Pf62 ZR1 and Pf62 ZR2) were negatives. It is very important to underline that the immunogenic capacity of a peptide not only depends on intrinsic chemical properties of the peptide but also on many complex interactions with various elements of the host immune system, such as the host immunoglobulin repertoire, self-tolerance, and various cellular and regulatory mechanisms definable only in the context of the host (Van Regenmortel 2001). Also, the high specificity showed the Pf62 ZR peptide is very important for the diagnosis because of the people living in malaria endemic areas with acquire immunity against malaria responded positively to all the malarial immunogens tested; however, the same persons also showed low specificity (Mannan et al. 2003). Besides, the Pf62 ZR peptide could be used to assess malaria transmission in epidemiological surveys similar to the studies carried out for Ferreira-da-Cruz et al. (1995). This study evaluated the antibody responses to P. falciparum sporozoite-, liver-, and blood-stage synthetic peptides in different populations in malaria endemic areas. On the other hand, the polyclonal antibodies against the Pf62 ZR peptide will be used for the development of diagnostic tests based on the capture of antigens. Some authors have studied the immunogenicity of synthetic peptides derived from $P$. falciparum proteins to obtain specific antibodies suitable to be used in an antigencapture assay (Zerpa et al. 2006).

In conclusion, this report describes the first approximation to characterization of Pf62, a new $P$. falciparum antigen that could be, if it is confirmed in further studies, a candidate for malaria diagnosis or malaria protection.

Acknowledgments This study was financially supported by the Spanish Ministry of Public Health and the Instituto de Salud Carlos III within the Network of Tropical Diseases Research Centers (RICETRD06/0021) by a grant from Centro Nacional de Medicina Tropical, Instituto de Salud Carlos III. None of the authors has any conflict of interest to declare. 
Open Access This article is distributed under the terms of the Creative Commons Attribution Noncommercial License which permits any noncommercial use, distribution, and reproduction in any medium, provided the original author(s) and source are credited.

\section{References}

Anders RF (1986) Multiple cross-reactivities amongst antigens of Plasmodium falciparum impair the development of protective immunity against malaria. Parasite Immunol 8:529-539

Aviv H, Leder P (1972) Purification of biologically active globin messenger RNA by chromatography on oligothymidylic acidcellulose. Proc Natl Acad Sci U S A 69:1408-1412

Bell D, Wongsrichanalai C, Barnwell JW (2006) Ensuring quality and access for malaria diagnosis: how can it be achieved? Nat Rev Microbiol 4:682-695

Bucher P, Bairoch A (1994) A generalized profile syntax for biomolecular sequences motifs and its function in automatic sequence interpretation. In: Proceedings 2nd International Conference on Intelligent Systems for Molecular Biology, Menlo Park

Devereux JR, Haeberli PL, Smithies O (1984) A comprehensive set of sequence analysis programmes for the VAX. NucleicAcic Res $12: 387-395$

Fenton B, Walker A, Walliker D (1985) Protein variation in clones of Plasmodium falciparum detected by two dimensional electrophoresis. Mol Biochem Parasitol 16:173-183

Ferreira-da-Cruz MF, Deslandes DC, Oliveira-Ferreira J, MontenegroJames S, Tartar A, Druilhe P, Daniel-Ribeiro CT (1995) Antibody responses to Plasmodium falciparum sporozoite-, liver- and blood-stage synthetic peptides in migrants and autochthonous populations in malaria endemic areas. Parasite 2(1):23-29

Guinet F, Dvorak JA, Fujioka H, Keister DB, Muratova O, Kaslow DC, Aikawa M, Vaidya AB, Wellems TE (1996) TEA developmental defect in Plasmodium falciparum male gametogenesis. J Cel Biol 135(1):269-278

Guinovart C, Navia MM, Tanner M, Alonso PL (2006) Malaria: burden of disease. Curr Mol Med 6(2):137-140

Herrera MI, Perez-Alvarez L, Cuevas L, Santa-Maria Y, FernandezCampo JA, Contreras G, Colomo C, Najera R (1998) Comparison of infectious HIV-1 and infected cell levels in blood and semen from seropositive men: quantitative data supporting viral compartmentalization in a follow-up study. J Hum Virol 1(2):148-149

Jameson BA, Wolf H (1988) The antigenic index: a novel algorithm for predicting antigenic determinants. Comput Appl Biosci 4 (1):181-186

Jones DT (1999) Protein secondary structure prediction based on position-specific scoring matrices. J Mol Biol 292:195-202
Kemp DJ, Cowman AF, Walliker D (1990) Genetic diversity in Plasmodium falciparum. Adv Parasitol 29:75-149

Kim YM, Hwang HA, Yun WS, Kim S, Lee KW, Park SK, Lee YJ, Kim TK, Wongsrichanalai C, Sakanari JA, Park H (2004) Efficacy of the merozoite surface protein 1 of Plasmodium vivax as an antigen for ELISA to diagnose malaria. Yonsei Medical $\mathrm{J}$ 45(1):129-134

Lobo CA, Kar SK, Ravindran B, Kabilan L, Sharma S (1994) Novel proteins of Plasmodium falciparum identified by differential immunoscreening using immune and patient sera. Inf Immun 62 (2):651-656

Makalowska I, Ryan JF, Baxevais AD (2001) GeneMachine gene prediction and sequence. Bioinformatics 17:843-844

Mannan BA, Patel K, Malhotra I, Ravindran B, Sharma S (2003) How specific is the immune response to malaria in adults living in endemic areas? J Vector Borne Dis 40(3-4):84-91

Maniatis T, Fritsch EF, Sambrook J (1982) Molecular cloning. In: Nolan C, Ferguson M, Ford N (eds) A laboratory manual. Cold Spring Harbor Laboratory Press, New York, pp 835-845

Rangel-Aldao R, Comach G, Mendoza, A (1987) A in vitro translation of $T$. cruzi antigens recognised by human chagasic sera. J Parasitol 73:855-857

Sambrook J, Fritsch EF, Maniatis T (1989) Molecular cloning. In: Nolan C, Ferguson M, Ford N (eds) A laboratory manual. Cold Spring Harbor Laboratory Press, New York, pp 9.16-9.22

Sanger F, Nicklen S, Coulson AR (1977) DNA sequencing with chain-terminating inhibitors. Pro Nat Aca Sci USA 74:54635467

Tait A (1981) Analysis of protein variation in Plasmodium falciparum by two-dimensional gel electrophoresis. Mol Biochem Parasitol 2:205-218

Trang DT, Huy NT, Kariu T, Tajima K, Kamei K (2004) One-step concentration of malarial parasite-infected red blood cells and removal of contaminating white blood cells. Malar J 17:3-7

Van Regenmortel MHV (2001) Antigenicity and immunogenicity of synthetic peptides. Biologicals 29:209-213

Wunderlich F, Helwig M, Schillinger G, Speth V (1988a) Cryptic disposition of antigenic parasite proteins in plasma membranes of erythrocytes infected with Plasmodium chabaudi. Mol Biochem Parasitol 30:55-65

Wunderlich F, Helwig M, Schillinger G, Speth V, Wiser MF (1988b) Expression of the parasite protein Pc90 in plasma membranes of erythrocytes infected with Plasmodium chabaudi. Eur J Cell Biol 47:157-164

Zerpa NC, Wide A, Noda J, Bermudez H, Pabon R, Noya OO (2006) Immunogenicity of synthetic peptides derived from Plasmodium falciparum proteins. Exp Parasitol 113(4):227-234

Zhang K, Fujioka H, Lobo CA, Kitayaporn D, Aikawa M, Kumar N (1999) Cloning and characterization of a new asparagine-rich protein in Plasmodium falciparum. Parasitol Res 85(12):956963 